\title{
EL RECURSO DE INCONSTITUCIONALIDAD CONTRA LA LEY DEL PARLAMENTO VASCO 9/2008, DE 27 DE JUNIO (Comentario al dictamen del Consejo de Estado $1.119 / 2008$, de 3 de julio de 2008)
}

\author{
SUMARIO \\ I. Competencia del Consejo de Estado para \\ emitir el dictamen. \\ II. Los antecedentes. \\ III. Las consideraciones del dictamen.
}

\section{COMPETENCIA DEL CONSEJO DE ESTADO PARA EMITIR EL DICTAMEN}

La Comisión Permanente del Consejo de Estado ha aprobado en sesión de 3 de julio de 2008, el dictamen núm. 1.119/2008, relativo a la interposición de recurso de inconstitucionalidad contra la Ley del Parlamento Vasco 9/2008, de 27 de junio, de convocatoria y regulación de una consulta popular al objeto de recabar la opinión ciudadana en la Comunidad Autónoma del País Vasco sobre la apertura de un proceso de negociación para alcanzar la paz y la normalización política.

El artículo 22.6 de la Ley Orgánica 3/1980, de 22 de abril, del Consejo de Estado, prescribe la consulta a su Comisión Permanente sobre la «impugnación de las disposiciones y resoluciones adoptadas por los órganos de las Comunidades Autónomas ante el Tribunal Constitucional, con carácter previo a la interposición del recurso". Comprende las vías impugnatorias del recurso de inconstitucionalidad (artículo 161.1 a) CE), de los conflictos de competencias (artículo 161.1. c) CE) y de la impugnación establecida en el Título V de la Ley Orgánica 2/1979, de 3 de octubre, del Tribunal Constitucional (artículo 161.2 CE). El Consejo de Estado examina en tales casos si hay fundamentos jurídicos suficientes para proceder a la impugnación que corresponda.

Cabe destacar que el artículo 22.6 de la Ley Orgánica 3/1980, fue modificado por la Ley Orgánica 3/2004, de 28 de diciembre. A partir de dicha Ley la consulta al Consejo de Estado ha de solicitarse, en todo caso, con carácter 
previo a la impugnación de la disposición o resolución autonómica. La redacción originaria del artículo 22.6 de la Ley Orgánica 3/1980 permitía que la consulta al Consejo de Estado tuviese carácter previo o posterior a la interposición del recurso. En ese último caso el Gobierno acordaría, en la misma sesión, interponer el recurso y formular la consulta. El Consejo de Estado en su Memoria de 1990 (y en parecido sentido en la Memoria de 1981) advirtió que lo que constituye una posibilidad (la consulta al Consejo de Estado con posterioridad a la interposición del recurso), legitimada pero excepcional por su naturaleza, ha devenido de hecho en una regla general, con la consiguiente pérdida de eficacia de la función consultiva, en cuanto debiera de servir para enjuiciar la legalidad y el acierto de la decisión impugnatoria y para procurar, si procede, su más sólida fundamentación. La Memoria del Consejo de Estado de 1982 subrayaba que "no puede ocultarse que es contrario a su propia naturaleza que un dictamen se emita después de tomada la decisión de lo que ha de ser objeto de aquel". No obstante, es preciso recordar que el Gobierno, en ocasiones, ha desistido de procesos constitucionales a la luz del dictamen negativo del Consejo de Estado. Así, a título de ejemplo, cabe señalar los dictámenes relativos a la Ley del Parlamento de Cataluña 9/1987, de 25 de mayo, de sucesión intestada, (51.040, de 7 de abril de 1988) y a la Ley 3/1992, de 1 de julio, del Derecho Civil Foral del País Vasco, (1537/1992, de 13 de julio de 1993 ), en los que el Consejo de Estado concluyó que no existían fundamentos jurídicos suficientes para mantener el recurso de inconstitucionalidad que ya había sido interpuesto.

Con la nueva redacción del artículo 22.6 de la Ley Orgánica 3/1980 todas las consultas en esta materia serán previas a la interposición del recurso de inconstitucionalidad. Así, se recupera la plena efectividad de la función consultiva que requiere que el dictamen sea conocido y valorado por el órgano competente para decidir. De esta manera se puede evitar, en algunos casos, que se interpongan delicados recursos con el riesgo de que no prosperen, concretar los motivos en que deberán fundarse y a los que convenga que se circunscriban y alegar las más sólidas razones y fundamentos jurídicos y constitucionales en los supuestos en que parezca procedente la interposición.

El problema que se presenta ahora es la remisión de los expedientes al Consejo de Estado con unos plazos perentorios (salvo cuando se hace uso de la posibilidad prevista en el artículo 33.2 de la Ley Orgánica 2/1979, de 3 de octubre, del Tribunal Constitucional, en la redacción dada por la Ley Orgánica $1 / 2000$, de 7 de enero, en cuyo caso el plazo de interposición del recurso de inconstitucionalidad es de nueve meses). De ello es buen reflejo la consulta sobre la Ley del Parlamento Vasco 9/2008, que fue registrada de entrada el día 2 de julio de 2008, siendo aprobado el dictamen al día siguiente, el 3 de julio de 2008, cuando la Ley había sido aprobada por el Parlamento Vasco (el 27 de junio de 2008) pero todavía no había sido publicada en el Boletín Oficial del País Vasco, lo que tuvo lugar el día 15 de julio de 2008. 


\section{LOS ANTECEDENTES}

El dictamen del Consejo de Estado sobre la Ley del Parlamento Vasco 9/2008, de 27 de junio, dedica la primera parte de los antecedentes a exponer el contenido de dicha Ley. Seguidamente hace referencia a la propuesta de acuerdo del Consejo de Ministros por el que se solicita del Presidente del Gobierno que promueva recurso de inconstitucionalidad ante el Tribunal Constitucional para la impugnación de la citada Ley, con expresa invocación del artículo 161.2 de la Constitución, de acuerdo con lo establecido en el artículo 30 de la Ley Orgánica del Tribunal Constitucional, a fin de que se produzca la suspensión de la vigencia de la norma objeto de recurso. La impugnación parte de que el artículo 9.2 e) del Estatuto de Autonomía del País Vasco no puede resultar título habilitante de la Ley de conformidad con el Ordenamiento Constitucional y de que todos los mecanismos de consulta previstos en nuestro ordenamiento requieren la autorización estatal para su ejercicio, requisito que se infringe en la Ley vasca. La Comunidad Autónoma del País Vasco carece de competencias en materia de consultas populares, por lo que el Estado ostenta todas las potestades normativas y ejecutivas en relación con los referendos que se celebren en dicha Comunidad Autónoma.

La impugnación de la Ley Vasca se fundamenta en dos tipos de reproches de inconstitucionalidad. Uno relativo a la falta de competencia de la Comunidad Autónoma para la convocatoria y otro relativo a la inconstitucionalidad de las decisiones que se propone someter a consulta. En el primer caso se vulnera lo dispuesto en el artículo 149.1.32 ${ }^{\mathrm{a}} \mathrm{CE}$ en relación con el artículo 92 CE ya que se sustituye la preceptiva autorización del Estado por una autorización del Parlamento Vasco, lo que intringe también distintas previsiones de la Ley Orgánica 2/1980, particularmente sus artículos 2, 3 y 6 y se atribuye al Lehendakari competencia para convocar el referéndum, aunque carece de competencia estatutariamente asumida para ello. Consecuencia de la ausencia de cobertura estatutaria es también la inconstitucionalidad de la disposición adicional y de sus disposiciones finales primera y segunda, tendentes a adaptar la Ley del País Vasco 5/1990, de 15 de junio, de Elecciones al Parlamento Vasco, al desarrollo de la convocatoria de un referéndum.

Por lo que atañe al contenido de la consulta, la propuesta de acuerdo del Consejo de Ministros la considera igualmente inconstitucional por vulnerar los artículos 1.2 y 2 de la Constitución e infringir lo dispuesto en el artículo 168 CE sobre la reforma constitucional.

El dictamen expone en sus últimos antecedentes el contenido de los informes de la Subsecretaría del Ministerio del Interior de 30 de junio de 2008 y de la Dirección General de Desarrollo Autonómico del Ministerio de Administraciones Públicas de 1 de julio de 2008, cuyos argumentos son semejantes a los contenidos en la propuesta de acuerdo del Consejo de Ministros. 


\section{LAS CONSIDERACIONES DEL DICTAMEN}

Las consideraciones del dictamen se ocupan fundamentalmente de tres cuestiones, la tramitación del procedimiento parlamentario seguido por la Ley $9 / 2008$, la competencia para convocar y regular la consulta objeto de dicha Ley y el contenido material de la consulta.

\section{III.1. EL PROCEDIMIENTO LEGISLATIVO SEGUIDO PARA LA TRAMITACIÓN DE LA LEY 9/2008}

La primera parte del dictamen del Consejo de Estado se dedica a examinar el contenido de la Ley y su incidencia en el procedimiento legislativo seguido para su tramitación. El dictamen examina el artículo único de la Ley del Parlamento Vasco en cuyo apartado 1 se formulan las preguntas que se pretende someter a consulta y en el apartado 2 se dice que la consulta se celebrará el sábado 25 de octubre de 2008 en la Comunidad Autónoma del País Vasco y se tendrá por convocada por el Lehendakari el día 15 de septiembre de 2008. Asimismo tiene en cuenta la disposición adicional de la Ley que procede a determinar el régimen jurídico aplicable al desenvolvimiento de la consulta.

El Consejo de Estado formula una primera observación de pura técnica normativa. Afirma el dictamen que, en virtud del artículo 1 de la Ley 9/2008, el Parlamento Vasco no sólo autoriza la consulta, sino que fija la fecha de celebración y su ámbito territorial y la tiene por convocada por el Lehendakari, el día 15 de septiembre de 2008. Por lo tanto, la Ley autoriza y convoca la consulta, aun cuando se entienda convocada por el Lehendakari, lo que parece excluir cualquier acto formal de convocatoria por parte del Presidente de la Comunidad Autónoma. Utiliza un técnica normativa confusa al mezclar, en los términos en que lo hace, la autorización y la convocatoria de la consulta, con el resultado de que el Presidente de la Comunidad Autónoma, al que se sitúa en la posición jurídica de convocante, queda vinculado por la Ley 9/2008 no sólo respecto del hecho mismo de la convocatoria, sino también de las fechas de celebración de la consulta y del momento en que se entiende por convocada, extremos que sólo podrían ser modificados mediante la tramitación de otra iniciativa legislativa. Esta observación, pertinente para mostrar una inicial perplejidad ante el uso y aplicación de las categorías jurídicas, no ha de tener aquí y ahora - dice el dictamen - otra trascedencia dado que, como ha afirmado el Tribunal Constitucional en numerosas ocasiones, eel juicio de constitucionalidad no lo es de técnica legislativa" (SSTC 341/1993, de 18 de noviembre, 137/2002, de 14 de febrero, y 179/2006, de 13 de junio).

A continuación, al examinar el trámite parlamentario seguido, advierte el Consejo de Estado que para la sustanciación parlamentaria del proyecto se ha aplicado el procedimiento de lectura única. El Acuerdo del Consejo de Gobierno Vasco funda tal aplicación en la "naturaleza singular y novedosa" 
del proyecto y en la "simplicidad de su enunciación y contenido" (un único artículo"), circunstancias - dice- que aconsejan su tramitación conforme a las normas del debate de la totalidad, sujetándose el conjunto del proyecto a una sola votación. A la "naturaleza y sencillez del proyecto" añade otras razones de carácter extraordinario que —a su juicio- han de atenderse sin mayor dilación y que aconsejan su tramitación, sin la previa autorización de la Cámara, por el procedimiento de lectura única. La parte expositiva de dicho Acuerdo finaliza constatando que el proyecto "no afecta al ordenamiento de las Instituciones de la Comunidad Autónoma, ni al régimen jurídico de las Instituciones Forales, ni a los derechos, deberes o libertades de los ciudadanos ni tampoco al régimen electoral dado que no contempla una modificación del régimen electoral sino, únicamente, la remisión al procedimiento electoral general con las necesarias adecuaciones por la índole del proceso consultivo a realizar".

Para el Consejo de Estado la utilización — como se ha hecho- del procedimiento de lectura única plantea serias dudas acerca de la posible vulneración del Reglamento del Parlamento Vasco de 11 de febrero de 1983 (RPV). El artículo 119 del RPV prescribe que, cuando la naturaleza del proyecto de ley lo aconseje o su simplicidad de formulación lo permita, el Pleno de la Cámara, a propuesta unánime de la Mesa, oída la Junta de Portavoces, podrá acordar que se tramite directamente en lectura única ante el Pleno o ante una Comisión. Adoptado tal acuerdo, se procederá a un debate sujeto a las normas establecidas para los de totalidad, sometiéndose seguidamente el conjunto del Proyecto a una sola votación. No se admite, pues, la presentación de enmiendas, como excepción a la regla general establecida por el artículo 102 RPV. Según el apartado 3 del artículo 119 RPV, "cuando circunstancias de carácter extraordinario y razones de urgente necesidad lo exijan, el Gobierno podrá hacer uso, sin requerir para ello la previa autorización de la Cámara, del procedimiento de lectura única, ante el Pleno o la Comisión correspondiente, para la tramitación de proyectos de ley que no afecten al ordenamiento de las Instituciones de la Comunidad Autónoma, el Régimen Jurídico de las Instituciones Forales, el Régimen Electoral, ni derechos, deberes o libertades de los ciudadanos".

Continua el dictamen afirmando que, teniendo en cuenta el contenido de la Ley 9/2008, no resulta amparada por el RPV la utilización por el Gobierno Vasco de la posibilidad de no requerir la previa autorización de la Cámara para la aplicación del procedimiento de lectura única. No se dan los "supuestos tasados", como los ha calificado el Tribunal Constitucional en su Sentencia 27/2000, de 31 de enero, enunciados en el artículo 119.3 RPV. Es evidente, al menos, que el contenido de la Ley afecta al ejercicio de un derecho fundamental, y así lo afirma expresamente la propia exposición de motivos de la Ley que califica a la consulta como "Vía sustancial para el ejercicio de un derecho fundamental reconocido en el artículo 9.2 del Estatuto de Autonomía", aunque en realidad se trate del contenido en el artículo 23.1 de la Constitución, y al régimen electoral, límites jurídicos expresamente impuestos 
por el artículo 119.3 RPV. La incidencia de la Ley en el régimen electoral resulta clara a la vista del contenido de la disposición adicional que adapta las previsiones de la Ley 5/1990 y del Decreto 330/1994, de 28 de julio, y sus posteriores modificaciones a la consulta de referencia.

Para el Consejo de Estado se ha prescindido del derecho de presentación de enmiendas en un supuesto en el que no concurren las circunstancias previstas por el RPV para ello. Tal derecho está vinculado al valor del pluralismo político (artículo 1.1 CE) y forma parte del status propio del cargo parlamentario al amparo del artículo 23.2 CE.

El Consejo de Estado recuerda que el Tribunal Constitucional ya en su STC 99/1987, de 11 de junio, declaró que, aunque el artículo 28 de la Ley Orgánica del Tribunal Constitucional "no menciona los Reglamentos parlamentarios entre aquellas normas cuya infracción puede acarrear la inconstitucionalidad de la Ley, no es dudoso que, tanto por la invulnerabilidad de tales reglas de procedimiento frente a la acción del legislador como, sobre todo, por el carácter instrumental que esas reglas tienen respecto de uno de los valores superiores de nuestro ordenamiento, el del pluralismo político (art. 1.1 $\mathrm{CE})$, la inobservancia de los preceptos que regulan el procedimiento legislativo podría viciar de inconstitucionalidad la ley cuando esa inobservancia altere de modo sustancial el proceso de formación de voluntad en el seno de las Cámaras".

Concluye esta parte del dictamen afirmando que el procedimiento legislativo seguido para la tramitación del proyecto de Ley no ha sido el idóneo de acuerdo con el RPV, al haberse utilizado una vía procedimentalmente inadecuada a la vista del alcance de la Ley objeto de impugnación, con la consiguiente vulneración de una norma que puede viciar la Ley.

\section{III.2. LA FALTA DE COMPETENCIA PARA LA CONVOCATORIA Y REGULACIÓN DE LA CONSULTA}

En el examen de la competencia del Parlamento Vasco para dictar la Ley, el Consejo de Estado analiza en primer lugar la naturaleza de la consulta objeto de la Ley 9/2008. Enjuicia si es correcta la calificación dada a la consulta popular prevista en dicha Ley, es decir, si se trata de una consulta popular por vía de referéndum -expresión utilizada por el artículo 149.1.32 ${ }^{\mathrm{a}}$ de la Constitución para atribuir al Estado la competencia sobre la autorización de su convocatoria- o no.

La exposición de motivos de la Ley del Parlamento Vasco considera que la consulta constituye un instrumento legal y democrático para que el pueblo vasco pueda ejercer libremente el derecho fundamental de participación ciudadana en los asuntos de trascendencia que son de su incumbencia. La consulta se somete a todos los ciudadanos y ciudadanas del País Vasco con derecho de sufragio activo como resulta de su artículo único. El cuerpo electoral ha de optar por el "Sí1" o por el "no", por el voto en blanco o por la abstención. 
El desarrollo de la consulta se regula por la Ley 5/1990, de 15 de junio, de Elecciones al Parlamento Vasco, con las adecuaciones derivadas del objeto de la votación. La utilización del censo, la Administración electoral, las garantías del derecho de sufragio activo y los demás elementos del sistema electoral rigen la consulta con las citadas adaptaciones. El objeto de la consulta es en palabras de la exposición de motivos de la Ley 9/2008, "la apertura de un proceso de negociación para alcanzar la paz y la normalización política, es decir, para exigir a ETA el fin de la violencia y, en una situación de abandono inequívoco de las armas, posibilitar un proceso de diálogo y, por otro lado, para abrir una negociación entre todos los partidos políticos con el objetivo de alcanzar un Acuerdo de normalización política en el que se establezcan las bases de una nueva relación entre la Comunidad Autónoma del País Vasco y el Estado español. En la formulación de la segunda pregunta se incluye, el sometimiento a referéndum del "Acuerdo Democrático sobre el ejercicio del derecho a decidir del Pueblo Vasco" antes de que finalice el año 2010.

Según el Consejo de Estado, la caracterización del ámbito y del contenido de la consulta ponen de manifiesto que forma parte del ejercicio del derecho a participar directamente en los asuntos públicos reconocido por el artículo 23.1 de la Constitución como expresión del principio de soberanía popular que preside el Estado social y democrático de Derecho en que España se constituye (artículo 1.1 y 2 de la Constitución). Como ha declarado el Tribunal Constitucional en su Sentencia 119/1995, de 17 de julio, shay una estrecha vinculación entre los derechos reconocidos en los apartados 1 y 2 del artículo 23 CE y el principio democrático, manifestación, a su vez, de la soberanía popular". Añade el Tribunal Constitucional en dicha Sentencia que "la participación directa que en los asuntos públicos ha de corresponder a los ciudadanos es la que se alcanza a través de las consultas populares previstas en la propia Constitución (artículos 92, 149.1.32, 151.1, 152.2, 167.3 y 168.3), (STC 63/1987, fundamento jurídico $5^{\circ}$ y ATC 399/1990, fundamento jurídico $2^{\circ}$ )"; “todos los preceptos enumerados se refieren a distintas modalidades de referéndum y, en última instancia, a lo que tradicionalmente se vienen considerando como formas de democracia directa, es decir, a aquellos supuestos en los que la toma de decisiones políticas se realiza mediante un llamamiento directo al titular de la soberanía", concluyendo más adelante que, "para determinar si estamos o no ante un derecho de participación política, encuadrable en el artículo 23.1 CE, habrá que atender, no sólo a la naturaleza y forma del llamamiento, sino también a su finalidad: sólo allí donde la llamada a la participación comporte, finalmente, el ejercicio, directo o por medio de representantes, del poder político - esto es, sólo allí donde se llame al pueblo como titular de ese poder- estaremos en el marco del artículo 23.1 CEn.

Considera el Consejo de Estado que de los términos de la Ley 9/2008 resulta que el llamamiento se hace a todos los ciudadanos y ciudadanas del País Vasco con derecho de sufragio activo - al pueblo vasco en palabras de la exposición de motivos- para que se pronuncie en relación con dos preguntas de carácter indudablemente político cuya trascendencia se subraya también 
por la propia exposición de motivos y con sometimiento a la regulación de las elecciones al Parlamento Vasco debidamente adaptada. Desde esta perspectiva (apelación al cuerpo electoral y decisiones políticas de especial trascendencia) ha de afirmarse que se trata, cuando menos, de un referéndum consultivo de perfiles similares al previsto en el artículo 92 de la Constitución, según el cual las decisiones políticas de especial trascendencia podrán ser sometidas a referéndum consultivo de todos los ciudadanos. La particularidad de este caso es la llamada a una fracción de todos los ciudadanos (el pueblo vasco) por una Ley del Parlamento Vasco. No se trata, pues, de una consulta no calificable de referéndum como lo sería una consulta limitada a tratar de conocer la opinión de la ciudadanía vasca por medios que no impliquen el ejercicio del derecho de sufragio (a través de encuestas, debates, o audiencias e informaciones públicas sin la trascendencia y efectos de las consultas por vía de referéndum).

A juicio del Consejo de Estado, la consulta es una manifestación encuadrable en las formas de democracia directa y no, en palabras de la Sentencia del Tribunal Constitucional 119/1995, de 17 de julio, de "un tertium genus que se ha denominado democracia participativa" y del que el texto constitucional - como también dice la Sentencia- es rico en manifestaciones. En este sentido el Tribunal Constitucional cita a continuación el artículo 9.2 CE que contiene un mandato a los poderes públicos para que faciliten «la participación de todos los ciudadanos en la vida política, económica, cultural y social" (precepto cuyo contenido es reiterado por el artículo 9.2 e) del Estatuto de Autonomía del País Vasco en relación con los poderes públicos vascos) y los artículos 48, 27.5 y 7, 105, 125, 129, 51, 52 y 131.2 CE. Considera el Tribunal Constitucional que «en el artículo 23.1 CE se trata de las modalidades - representativa y directa - de lo que en el mundo occidental se conoce por democracia política, forma de participación inorgánica que expresa la voluntad general, mientras que en los restantes preceptos a que se hecho alusión —si se exceptúa el jurado- (...) se da entrada a correctivos particularistas de distinto orden".

Para el Consejo de Estado la constante utilización por la Ley 9/2008 de la expresión "consulta" no modifica su naturaleza de referéndum. La exposición de motivos declara que no es una consulta popular por vía de referéndum (aunque la propia Ley sí califica de "referéndum" el previsto en la segunda pregunta objeto de consulta) e insiste en que no es jurídicamente vinculante, siendo este uno de los fundamentos para estimar que no es aplicable la Ley Orgánica 2/1980, de 18 de enero, ni la previa autorización del Estado para su convocatoria, a pesar de que el referéndum previsto en el artículo 92.1 de la Constitución y comprendido en la Ley Orgánica 2/1980 sea asimismo de carácter consultivo.

Añade el dictamen que el carácter consultivo y no vinculante de una consulta popular sólo pone de manifiesto que es anterior a la ejecución de una decisión y que no se inserta necesariamente en un acto formal del procedimiento de su materialización: la adopción de las medidas políticas o legislativas que sean necesarias para que los órganos competentes doten de virtuali- 
dad jurídica a la decisión será posterior. En la consulta vinculante, en cambio, se propone una ratificación por el electorado de su objeto y forma parte del procedimiento de adopción de la medida de que se trate (normalmente legislativa). En la práctica, sin embargo, los efectos de ambos tipos de consultas se aproximan significativamente. En la realidad política difícilmente un órgano del Estado podrá actuar en contra de la voluntad popular formalmente expresada, al ser ésta el fundamento mismo del principio democrático que informa la Constitución (artículo 1.1 CE). La autoridad - el plus de legitimidad- de la manifestación directa de la voluntad popular hace que el órgano llamado a decidir se encuentre vinculado políticamente por la opción popular. Esa fuerza vinculante estará en función de la nitidez de los resultados, siendo máxima cuando el electorado se haya decantado muy mayoritariamente por una de las alternativas. Ello es especialmente evidente cuando el resultado de la consulta es claramente negativo a la decisión consultada, en cuyo caso dicho resultado, además de impedir la formalización de la decisión, puede provocar otras consecuencias políticas derivadas de la falta de sintonía entre la voluntad de los ciudadanos y el poder público (a.e. elecciones anticipadas), mientras que, en el supuesto de que la opción de la voluntad popular sea favorable a la decisión que se pretende adoptar, podrá apreciarse una cierta discrecionalidad en el impulso y adopción de las iniciativas políticas o normativas necesarias para materializar la decisión. Pero en cualquier caso, la mayor o menor vinculación jurídica de su resultado no altera en nada el carácter de referéndum o no de la consulta.

El Consejo de Estado estima que la propia Ley objeto de impugnación, a pesar de referirse expresamente en su artículo único y en su exposición de motivos (en cinco ocasiones) al carácter "no vinculante" de la consulta, reconoce en esta última - por dos veces - su carácter "habilitador", del que se infiere, al menos, una vinculación negativa para el caso de que el resultado de las dos preguntas sea el "no" (la consulta no habilitaría para adoptar la decisión) y una habilitación positiva para el triunfo del "sín (sin perjuicio de que la respuesta mayoritaria a las preguntas pueda no ser la misma en los dos casos). Aunque la consulta habilite pero no obligue, el compromiso político que asume la autoridad convocante es expresivo de la efectiva autovinculación que se produce por el resultado positivo para llevar a cabo la decisión de que se trate. Sólo un sustancial cambio de circunstancias, debidamente motivado, podría justificar la falta de ejecución de la voluntad popular.

A juicio del Consejo de Estado, la consulta objeto de la Ley 9/2008 es una auténtica "consulta por vía de referéndum", en cuanto efectúa un llamamiento para que el electorado se pronuncie con sujeción al régimen electoral (adaptado), siendo su objeto el mismo previsto por el artículo 92 de la Constitución para el referéndum consultivo: una decisión política de especial trascendencia. Es aplicable, pues, el artículo 5 de la Ley Orgánica 2/1980, de 18 de enero, reguladora de las distintas modalidades de referéndum, según el cual «el referéndum se decidirá por sufragio universal, libre, igual, directo y secreto en el ámbito que corresponda a la consulta". 
Determinada la naturaleza de la consulta, el Consejo de Estado pasa a analizar el orden constitucional de competencias en la materia.

Comienza afirmando el dictamen que la Constitución consagra un sistema de democracia representativa en el que los resortes de democracia directa tienen un carácter muy limitado y circunscrito a los supuestos constitucionalmente previstos; las apelaciones al pueblo son excepcionales, por lo que carecen de cualquier género de vis expansiva. Entre los instrumentos de democracia directa, el referéndum consultivo permite instar la manifestación de la voluntad directa del pueblo sobre cualquier decisión política de especial trascendencia, por lo que tiene una relevancia capital en el juego de los poderes del Estado. Su regulación requiere el establecimiento de las debidas cautelas en garantía de la lealtad constitucional. Ello hace que el ordenamiento deba disciplinar esta forma de participación popular. La Constitución y el legislador han de racionalizar las manifestaciones directas de la voluntad popular. La utilización de mecanismos de esta naturaleza sin una regulación jurídica podría generar situaciones políticamente insostenibles, erráticas o de gran inestabilidad con eventual lesión del propio orden constitucional. La juridificación de tales instrumentos es una exigencia de la misma Constitución.

Recuerda el dictamen que el Tribunal Constitucional ha declarado en su STC 76/1994, de 14 de marzo, que los derechos de participación directa "Sólo tienen el alcance que deriva del ordenamiento vigente" y que "resulta necesario poner de manifiesto de entrada que el derecho a participar directamente en los asuntos públicos, como todos los derechos que la Constitución establece, no puede sino ejercerse en la forma jurídicamente prevista en cada caso. Lo contrario, lejos de satisfacer las exigencias de la soberanía popular, supondría la imposibilidad misma de existencia del ordenamiento a cuya obediencia todos — ciudadanos y poderes públicos- vienen constitucionalmente obligados (art 9.1 CE)". Más adelante dice que "también en la Comunidad Autónoma del País Vasco el pueblo no tiene mas derechos de participación política que los que le reconoce el ordenamiento vigente y en la forma de gobierno establecida en la Comunidad Autónoma priman también los mecanismos de democracia representativa". El carácter excepcional de los mecanismos de democracia directa se ha puesto de relieve por la STC 119/1995, de 17 de julio, según la cual «y aun si se admitiera que la Ley puede ampliar los casos de participación directa, los supuestos habrían de ser, en todo caso, excepcionales en un régimen de democracia representativa como el instaurado por nuestra Constitución, en el que priman los mecanismos de democracia representativa sobre los de participación directa (STC 76/1994)".

Para el Consejo de Estado la utilización de los mecanismos de democracia directa sólo puede hacerse de acuerdo y en la medida de lo establecido por los artículos de la Constitución que expresamente los reconocen y por la legislación dictada en su desarrollo.

El artículo 92 CE prevé en su apartado 3 que una Ley orgánica regulará las condiciones y el procedimiento de las distintas modalidades de referén- 
dum previstas en la Constitución. Además, el referéndum, en cuanto modalidad de participación directa en los asuntos públicos, implica el ejercicio de ese derecho fundamental reconocido por el artículo $23.1 \mathrm{CE}$, por lo que su desarrollo está sujeto a la reserva de ley orgánica prevista en el artículo $81 \mathrm{CE}$. Concurren así dos reservas de Ley Orgánica, una específica y otra más general sobre el desarrollo de los derechos fundamentales. A continuación el dictamen se refiere a los preceptos constitucionales que regulan alguna modalidad de referéndum (artículos 92, 151, 152, 167.3 y 149.1.32 ${ }^{\mathrm{a}}$ ).

Observa el Consejo de Estado que ni la Constitución ni las leyes dictadas en desarrollo de los anteriores preceptos constitucionales regulan una consulta popular de ámbito autonómico con los perfiles que le atribuye la Ley del Parlamento Vasco, es decir, sin autorización previa del Estado y sin sometimiento a lo dispuesto en la Constitución y en las Leyes Orgánicas de desarrollo, lo cual es ya motivo suficiente para excluir tal posibilidad.

Seguidamente el dictamen se refiere a la regulación de las consultas municipales (no mencionadas en la Constitución) por la disposición adicional de la Ley Orgánica 2/1980 y por el artículo 71 de la Ley 7/1985, de 2 de abril, reguladora de las Bases del Régimen Local, de cuyos términos el Tribunal Supremo ha dicho que arevelan un designio del legislador ciertamente restrictivo respecto de esta fórmula de participación popular en el procedimiento de adopción de decisiones municipales, inspirado en el sistema de representatividad electiva" (STS de 17 de febrero de 2000).

El Consejo de Estado también examina la regulación de las consultas populares en los Estatutos de Autonomía tanto en su redacción originaria como en la vigente. A la vista de ello observa que en las consultas populares por vía de referéndum han de ser respetadas la Constitución y la legislación orgánica dictada en su desarrollo, siendo necesaria, por tanto, la autorización del Estado. Destaca que en las últimas reformas estatutarias se prevén fórmulas de consulta a la opinión pública que nada tienen que ver con la directa expresión de la voluntad popular y el completo mecanismo de garantías, propio de la legislación electoral a que se refiere la Ley 9/2008. Destaca que algunos Estatutos de Autonomía no contienen ninguna mención de las consultas populares como es el caso de la Comunidad Autónoma del País Vasco.

El dictamen menciona las referencias del Estatuto de Autonomía del País Vasco a un referéndum que están contenidas en los artículos 8, que trata de la agregación de otros territorios o municipios enclavados en su totalidad (por ello no pertenecientes al País Vasco) en su territorio y establece como uno de los requisitos el acuerdo de los habitantes del Municipio o territorio mediante "referéndum expresamente convocado, previa la autorización competente al efecto y aprobado por mayoría de los votos válidos emitidos", y 46 y 47, relativos al procedimiento de reforma del Estatuto. El primero, tras requerir la aprobación de los electores mediante referéndum, prevé que el Gobierno Vasco podrá ser facultado, por delegación expresa del Estado, para convocar los referéndum a que se refiere dicho artículo. El artículo 47 en su apartado 1.c) se refiere a que en la situación que contempla "se convocará, debidamente 
autorizado, un referéndum sobre el texto propuesto". Estos preceptos prevén la preceptiva autorización estatal (o la delegación por el Estado de la convocatoria) y entre ellos no se encuentra ninguno que atribuya a la Comunidad Autónoma competencia sobre consultas populares. Por otra parte, el artículo 9.2. del Estatuto del País Vasco, invocado por la exposición de motivos de la Ley, no atribuye ninguna competencia específica para su cumplimiento pues, como declaró el Tribunal Constitucional ya en su Sentencia 25/1981, de 14 de julio, "no contiene una norma atributiva de competencia, es decir una norma que habilite a los poderes públicos vascos para actuar en una determinada materia en la que carecerían de atribuciones de no existir aquélla. Antes bien, lo que hace este precepto es concretar con respecto a los poderes públicos vascos unas obligaciones impuestas por la Constitución a todos los poderes públicos y que éstos, sin excepción, deben cumplir en el ámbito de sus competencias respectivas". Más adelante añade la Sentencia que ello "lo demuestra el propio artículo 9 del Estatuto de Autonomía del País Vasco que, al aludir a los deberes reseñados de los poderes públicos vascos, precisa que éstos se desarrollarán "en el ámbito de su competencia". Se pone con ello de relieve que el precepto no puede ser entendido autónomamente como una norma habilitante de competencia, sino que debe ser puesto en relación con los restantes preceptos del Estatuto que determinan las correspondientes competencias".

Concluye esta parte el dictamen afirmando que cabe apreciar, por lo tanto, la total falta de adecuación de la consulta regulada por la Ley 9/2008 a los artículos 92 y 149.1.32 ${ }^{\text {a }}$ CE y a la Ley Orgánica 2/1980. Se convoca la consulta sin la autorización previa estatal, con la sola autorización del Parlamento Vasco, por lo que ni siquiera se aplican las previsiones del Estatuto de Autonomía del País Vasco para otros referendos (artículos 46.2 y 47.1). La convocatoria se considera hecha por el Lehendakari, que carece de competencias para ello, ya que no se ha producido ninguna delegación expresa del Estado como la prevista en el artículo 46.2 del Estatuto de Autonomía. Y, aunque la Ley 9/2008 invoca como título habilitante de la consulta el artículo 9.2 del Estatuto, es lo cierto que este precepto no es atributivo de competencia y que restringe la actuación de los poderes públicos vascos al ámbito estricto de sus propias competencias, límite éste que, como se verá, ha sido excedido. Continúa el dictamen afirmando que, en realidad, tampoco se respetan las normas relativas al régimen electoral que habrían de aplicarse en el desarrollo de la consulta y que están contenidas en la Ley Orgánica 2/1980, de 18 de enero, cuyo capítulo II (artículos 11 a 19) se dedica al procedimiento para la celebración del referéndum. Aunque algunas de las normas contenidas en la disposición adicional de la Ley 9/2008 vienen a reproducir artículos de la Ley Orgánica 2/1980 (ha de recordarse que la STC 341/2005, de 21 de diciembre consideró que la reproducción de una norma estatal se convierte en ilegítima cuando la Comunidad Autónoma carece de competencia para legislar sobre una materia), otras omiten prescripciones de dicha Ley o contienen una regulación distinta de la aplicable Ley Orgánica 5/1985, de 19 de junio, de Régimen Electoral General, en relación con el sistema de subvención de los gas- 
tos electorales, como subraya el informe de la Subsecretaría del Ministerio del Interior. La Ley 9/2008 vulnera, por consiguiente, lo dispuesto en los artículos 92 y $149.1 .32^{a}$ CE y en la Ley Orgánica 2/1980, de 18 de enero, sobre modalidades de referéndum, tanto en lo relativo a la convocatoria de la consulta como en lo concerniente a las normas reguladoras de su desarrollo.

\section{III.3. EL OBJETO DE LA CONSULTA POPULAR}

La última parte del dictamen se dedica a examinar el objeto de la consulta que constituye el núcleo esencial de la Ley en cuestión.

Para el Consejo de Estado su contenido evidencia la imposibilidad, sin la consiguiente dislocación del orden constitucional, de que éste pueda admitir el traslado, sin más, del ámbito de libertad previsto en el artículo 92.1 de la Constitución para el objeto (decisiones políticas de especial trascendencia) de un referéndum consultivo "de todos los ciudadanos" a una consulta por vía de referéndum de una fracción del cuerpo electoral (el pueblo vasco) sin limitarse al ámbito de competencias y de intereses estrictamente autonómicos.

Añade el dictamen que el objeto de la consulta, formulado en términos de pregunta al electorado vasco por el artículo único de la Ley y precisado por los términos de la exposición de motivos, trasciende el ámbito de interés y de competencias de la Comunidad Autónoma, afecta al interés del Estado y de los demás territorios de España. La admisión de una consulta como la examinada pondría en riesgo el orden constitucional del Estado y las bases mismas en que se asienta (artículos 1.2 CE, que afirma la soberanía nacional del pueblo español y no de fracciones del mismo, y $2 \mathrm{CE}$, que fundamenta la indisoluble unidad de la Nación española).

El Consejo de Estado considera que la autonomía política no puede legitimar el pronunciamiento de una parte del electorado acerca de una decisión de orden constitucional que - como subraya uno de los órganos preinformantes - afecta a aspectos esenciales de todo el Estado y a todos los poderes públicos en general». Sobre una cuestión de tales características se requeriría una decisión soberana del pueblo español. El cuerpo electoral autonómico no puede condicionar las decisiones de interés "de todos los ciudadanos" No debe olvidarse, como destaca la Sentencia del Tribunal Constitucional 247/2007, de 12 de diciembre, sobre la reforma del Estatuto de Autonomía de la Comunidad Valenciana, que la estructuración del poder del Estado se basa, según la Constitución, en el principio de unidad, fundamento de la propia Constitución y en los de autonomía y solidaridad. La autonomía, añade la citada Sentencia "hace referencia a un poder limitado. En efecto, autonomía no es soberanía y, dado que cada organización dotada de autonomía es una parte del todo, en ningún caso el principio de autonomía puede oponerse al de unidad, sino que es precisamente dentro de éste donde alcanza su verdadero sentido, como expresa el artículo 2 de la Constitución". Y más adelante recuerda la STC 76/1988, de 26 de abril, en la que se afirmó que el Es- 
tado autonómico se asienta en el principio fundamental de que nuestra Constitución hace residir la soberanía nacional en el pueblo español (art. 1.2 CE), de manera que aquella no es el resultado de un pacto entre instancias territoriales históricas que conserven unos derechos anteriores a la Constitución y superiores a ella, sino una norma del poder constituyente que se impone con fuerza vinculante general en su ámbito, sin que queden fuera de ella situaciones históricas anteriores.

En particular, observa el Consejo de Estado, por lo que atañe a la pregunta b) del apartado 1 del artículo único de la Ley 9/2008, los esfuerzos argumentales no velan, sino que evidencian con nitidez, la realidad. La exposición de motivos declara que se trata de abrir una negociación entre todos los partidos políticos con el objetivo de alcanzar un Acuerdo de normalización política en el que se establezcan las bases de una nueva relación entre la Comunidad Autónoma del País Vasco y el Estado español». Pero, dado que los términos de la articulación del Estado y de las entidades territoriales en que se organiza están constitucionalmente predeterminados, cualquier cambio en los mismos llevaría a una confrontación con la Constitución vigente. Además, someter a consulta del electorado de una Comunidad Autónoma una decisión que pretende alterar la estructuración misma del poder del Estado implicaría quebrantar la Constitución en lo que respecta a su reforma con vulneración de su artículo 168 que prevé, para tal reforma, un referéndum de ratificación con participación de todo el cuerpo electoral. A lo que debe añadirse que el artículo 166 de la Constitución, al regular la iniciativa de reforma constitucional, se remite a los apartados 1 y 2 del artículo 87 que excluye la iniciativa popular, lo que constituye una manifestación más de la primacía de la democracia representativa.

El Consejo de Estado entiende que la admisión de la iniciativa vasca, en suma, supondría aceptar que una fracción del electorado pudiera, en hipótesis, abrir un auténtico proceso constituyente, expresándose, con crudeza, no sólo la tensión entre una democracia representativa y los instrumentos de participación directa, sino también entre el pueblo español como titular de la soberanía nacional y una parte del mismo a la que se le reconocería en la práctica una capacidad exorbitante de las competencias de ámbito territorial limitado y afectantes al orden constitucional establecido. En términos de la Sentencia del Tribunal Constitucional 247/2007, "la distinción entre poder constituyente y poderes constituidos no opera sólo en el momento de establecerse la Constitución"; "la voluntad y racionalidad del poder constituyente objetivadas en la Constitución no sólo fundan en su origen sino que fundamentan permanentemente el orden jurídico y estatal y suponen un límite a la potestad del legislador"; "al Tribunal Constitucional corresponde custodiar la permanente distinción entre la objetivación del poder constituyente y la actuación de los poderes constituidos, los cuales nunca podrán rebasar los límites y las competencias establecidas por aquél».

Finaliza el dictamen afirmando que, de todo lo anterior resulta la inconstitucionalidad de la Ley a que se refiere la consulta, en cuanto pone en 
cuestión el fundamento mismo del orden político-jurídico del Estado en su conjunto y es consecuente, además, a una iniciativa legislativa aprobada por el Parlamento Vasco, vulnerando el orden constitucional de competencias. Resulta necesaria, dice el dictamen, la interposición en cuanto proceda de un recurso de inconstitucionalidad contra dicha Ley a fin de evitar la adopción de cualquier disposición en su desarrollo que, caso de ser dictada, también resultaría afectada por los mismos motivos de inconstitucionalidad.

La conclusión del dictamen es "que existen fundamentos jurídicos suficientes para interponer recurso de inconstitucionalidad contra la Ley del Parlamento Vasco 9/2008, de 27 de junio, de convocatoria y regulación de una consulta popular al objeto de recabar la opinión ciudadana en la Comunidad Autónoma del País Vasco sobre la apertura de un proceso de negociación para alcanzar la paz y la normalización política".

Con posterioridad a la aprobación del dictamen del Consejo de Estado reseñado, el Presidente del Gobierno, a solicitud de éste en reunión del Consejo de Ministros de 4 de julio de 2008, acordó interponer el recurso de inconstitucionalidad contra la Ley 9/2008. Su interposición se realizó el 15 de julio de 2008 y el 17 de julio de 2008 el Pleno del Tribunal Constitucional acordó admitirlo a trámite. La Sentencia del Pleno del Tribunal Constitucional 103/2008, de 11 de septiembre (BOE de 10 de octubre de 2008), acordó estimar el citado recurso núm. 5707/2008 y, en consecuencia, declarar la inconstitucionalidad y consiguiente nulidad de la Ley del Parlamento Vasco 9/2008, de 27 de junio, de convocatoria y regulación de una consulta popular al objeto de recabar la opinión ciudadana en la Comunidad Autónoma del País Vasco sobre la apertura de un proceso de negociación para alcanzar la paz y la normalización política.

Title: Appeal against the Basque Parliament Act $n^{\circ}$ 9/2008, of 27 of june (Comment on the Council of State Legal Opinion).

ABstRACT: Comment on the Council of State Legal Opinion about the Appeallodged in the Constitutional Court against the Basque Parliament Act related to the official announcement and regulation of a referendum.

RESUMEN: Notas al Dictamen del consejo de Estado sobre la interposición de recurso de inconstitucionalidad contra la Ley del Parlamento Vasco de convocatoria y regulación de una consulta popular.

KEY WORDS: Council of State. Legal Opinion. Referendum.

Palabras clave: Consejo de Estado. Dictamen. Referéndum. 